\title{
Ultrasensitive Photodetectors Based on Strongly Interacted Layered-Perovskite Nanowires
}

Meng Yuan ${ }^{1,2}$, Yingjie Zhao ${ }^{1,2}$, Jiangang Feng ${ }^{3 *}$, Hanfei Gao ${ }^{1,4}$, Jinjin Zhao ${ }^{1,2}$, Lei Jiang ${ }^{1,4}$, Yuchen $W u^{1,4 *}$

${ }^{1}$ Key Laboratory of Bio-inspired Materials and Interfacial Science, Technical Institute of Physics and Chemistry, Chinese Academy of Sciences, Beijing 100190, P. R. China

${ }^{2}$ University of Chinese Academy of Sciences (UCAS), Beijing 100049, P. R. China

${ }^{3}$ Department of Chemical and Biomolecular Sciences, National University of Singapore, Singapore 117585 , Singapore

${ }^{4}$ Ji Hua Laboratory, Foshan 528000, Guangdong, P. R. China.

*E-mails: j.feng@nus.edu.sg, wuyuchen@iccas.ac.cn 


\section{Note S1. Fabrication of asymmetric-wettability topographical template.}

The asymmetric-wettability topographical template was fabricated using silicon wafers $(<100>$ oriented, $\mathrm{N}$ doped, $10 \mathrm{~cm}$ diameter, $525 \mu \mathrm{m}$ thickness). The predesigned patterns were first transferred onto the photoresist (Shipley Microposit S1800 series), which was coated onto the silicon wafer with about $1 \mu \mathrm{m}$ thickness, and then a direct laser writing apparatus (Heidelberg DWL200) was performed. After irradiation and development, the micropillar structure was etched using deep reactive-ion etching (DRIE, Alcatel 601E) with fluorine-based reagents for 6 min. Pillar-structured silicon substrates with a pillar gap of $5 \mu \mathrm{m}$, a width of $2 \mu \mathrm{m}$, and a height of $20 \mu \mathrm{m}$ were fabricated. After resist stripping (Microposit Remover 1165), the templates with micropillars were cleaned with acetone and ethanol before use. To fabricate asymmetric-wettability micropillar, selective modification of micropillar using heptadecafluorodecyltrimethoxysilane (FAS) was carried out, resulting in hydrophobic sidewalls with FAS molecular and hydrophilic tops without FAS molecular of the micropillar template. 
Note S2. Synthesis of (MTEA) $)_{2}(\mathrm{MA})_{n-1} \mathrm{~Pb}_{n} \mathrm{I}_{3 n+1}(n=1-3)$ layered perovskite flakes.

$(\mathrm{MTEA})_{2} \mathrm{PbI}_{4}(n=1) . \mathrm{PbO}$ powder $(558 \mathrm{mg}, 2.5 \mathrm{mmol})$ was dissolved in a mixture of $57 \% \mathrm{w} / \mathrm{w}$ aqueous $\mathrm{HI}$ solution $(2.5 \mathrm{~mL}, 19 \mathrm{mmol})$ and $50 \%$ aqueous $\mathrm{H}_{3} \mathrm{PO}_{2}(0.5 \mathrm{~mL}, 4.55 \mathrm{mmol})$ by heating to $180{ }^{\circ} \mathrm{C}$ for about 15 min under magnetic stirring forming a bright yellow solution. Methylamine chloride (MACl) $(84.4 \mathrm{mg}, 1.25 \mathrm{mmol})$ was added to the hot yellow solution resulting in the precipitation of black powder, which was rapidly redissolved to a clear bright yellow solution under stirring for about $20 \mathrm{~min}$. After adding 2-(methylthio)ethyla mine hydrochloride (MTEACl) (319.2 $\mathrm{mg}, 2.5 \mathrm{mmol}$ ) to the $\mathrm{PbI}_{2}$ solution, an orange precipitate was produced, which was subsequently dissolved by heating the solution to boiling. The stirring was then discontinued, and the solution was left to cool to room temperature for $3 \mathrm{~h}$ during which time orange rectangular-shaped plates started to crystallize. The crystals were washed using toluene, isolated by suction filtration, and thoroughly dried under reduced pressure.

(MTEA) $)_{2}(\mathrm{MA}) \mathrm{Pb}_{2} \mathrm{I}_{7}(n=2) . \mathrm{PbO}$ powder $(558 \mathrm{mg}, 2.5 \mathrm{mmol})$ was dissolved in a mixture of $57 \%$ w/w aqueous $\mathrm{HI}$ solution $(2.5 \mathrm{~mL}, 19 \mathrm{mmol})$ and $50 \%$ aqueous $\mathrm{H}_{3} \mathrm{PO}_{2}(0.5 \mathrm{~mL}, 4.55 \mathrm{mmol})$ by heating to $180{ }^{\circ} \mathrm{C}$ for about $15 \mathrm{~min}$ under magnetic stirring forming a bright yellow solution. Methylamine chloride (MACl) $(84.4 \mathrm{mg}, 1.25 \mathrm{mmol})$ was added to the hot yellow solution resulting in the precipitation of black powder, which was rapidly redissolved to a clear bright yellow solution under stirring for about $20 \mathrm{~min}$. After adding 2-(methylthio)ethyla mine hydrochloride (MTEACl) (159.6 $\mathrm{mg}, 1.25 \mathrm{mmol}$ ) to the $\mathrm{PbI}_{2}$ solution, an orange precipitate was produced, which was subsequently dissolved by heating the solution to boiling. The stirring was then discontinued, and the solution was left to cool to room temperature for $3 \mathrm{~h}$ during which time deep-red rectangular-shaped plates started to crystallize. The crystals were washed using toluene, isolated by suction filtration, and thoroughly dried under reduced pressure. 
$(\mathrm{MTEA})_{2}(\mathrm{MA})_{2} \mathrm{~Pb}_{3} \mathrm{I}_{10}(n=3) . \mathrm{PbO}$ powder $(558 \mathrm{mg}, 2.5 \mathrm{mmol})$ was dissolved in a mixture of $57 \% \mathrm{w} / \mathrm{w}$ aqueous $\mathrm{HI}$ solution $(2.5 \mathrm{~mL}, 19 \mathrm{mmol})$ and $50 \%$ aqueous $\mathrm{H}_{3} \mathrm{PO}_{2}(0.5 \mathrm{~mL}, 4.55 \mathrm{mmol})$ by heating to $180{ }^{\circ} \mathrm{C}$ for about 15 min under magnetic stirring forming a bright yellow solution. Methylamine chloride (MACl) $(112.6 \mathrm{mg}, 1.67 \mathrm{mmol})$ was added to the hot yellow solution resulting in the precipitation of black powder, which was rapidly redissolved to a clear bright yellow solution under stirring for about $20 \mathrm{~min}$. After adding 2-(methylthio)ethyla mine hydrochloride (MTEACl) $\left(106.3 \mathrm{mg}, 0.83 \mathrm{mmol}\right.$ ) to the $\mathrm{PbI}_{2}$ solution, an orange precipitate was produced, which was subsequently dissolved by heating the solution to boiling. The stirring was then discontinued, and the solution was left to cool to room temperature for $3 \mathrm{~h}$ during which time black rectangular-shaped plates started to crystallize. The crystals were washed using toluene, isolated by suction filtration, and thoroughly dried under reduced pressure. 
a

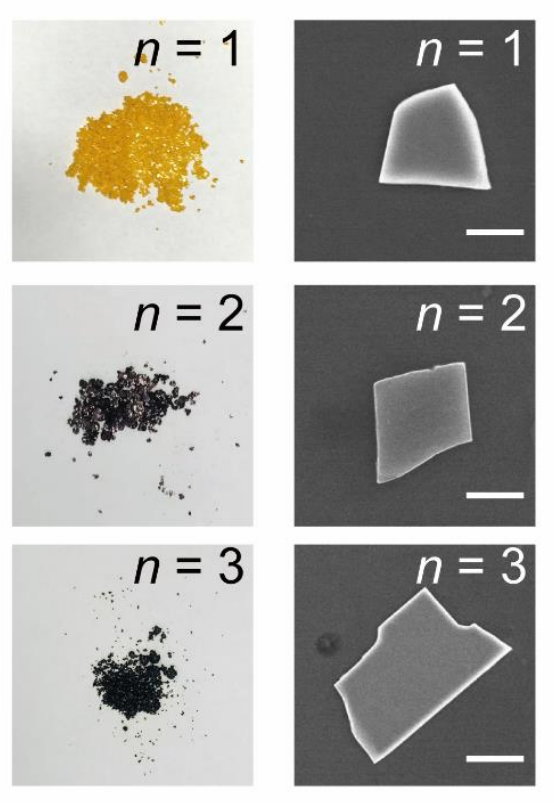

b

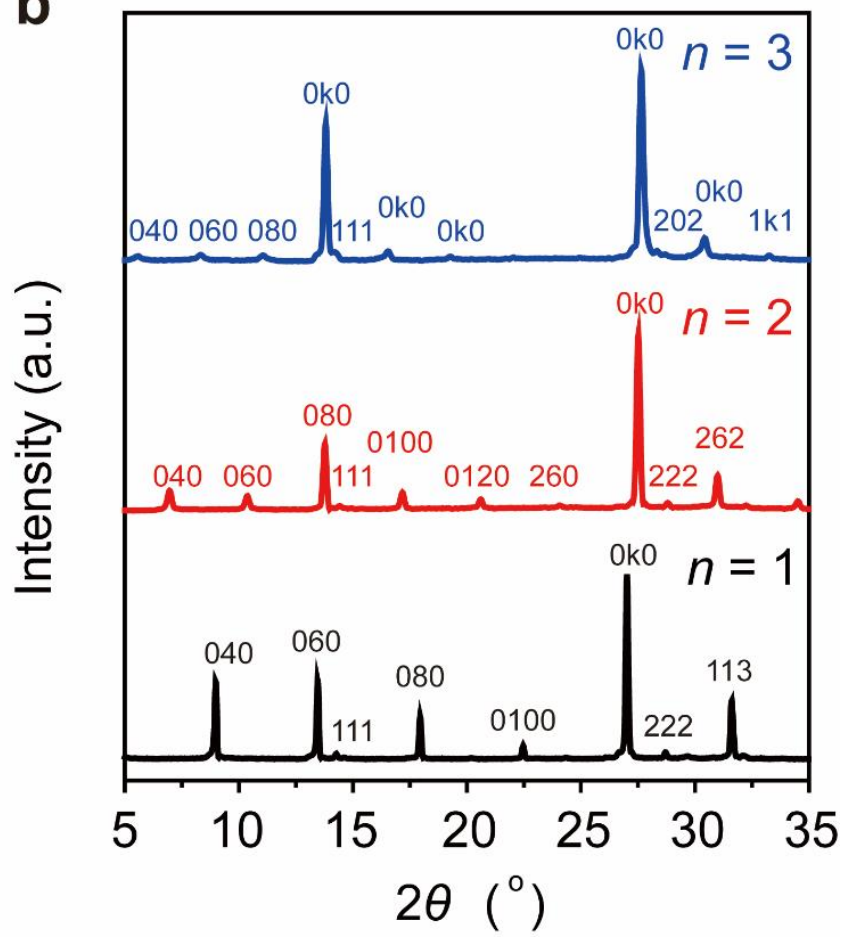

Figure S1. Layered perovskite of (MTEA $)_{2}(\mathrm{MA})_{n-1} \mathrm{~Pb}_{n} \mathrm{I}_{3 n+1}(n=1-3)$ bulk crystals. a) Photograph and SEM images of synthesized layered-perovskite bulk crystals. b) X-ray diffraction characterizations of perovskite powders. A series of diffraction peaks of $(h k l)$ planes on the low-angle region ( $2 \theta$ of $5^{\circ}$ to $20^{\circ}$ ) distinguish the perovskites with different layer numbers. Due to the similar lattice parameter $a$ and $c$ of 2DRP perovskite crystals, the $2 \theta$ of (111), (222), and (202) present negligible differences. Scale bars, $5 \mu \mathrm{m}$. 

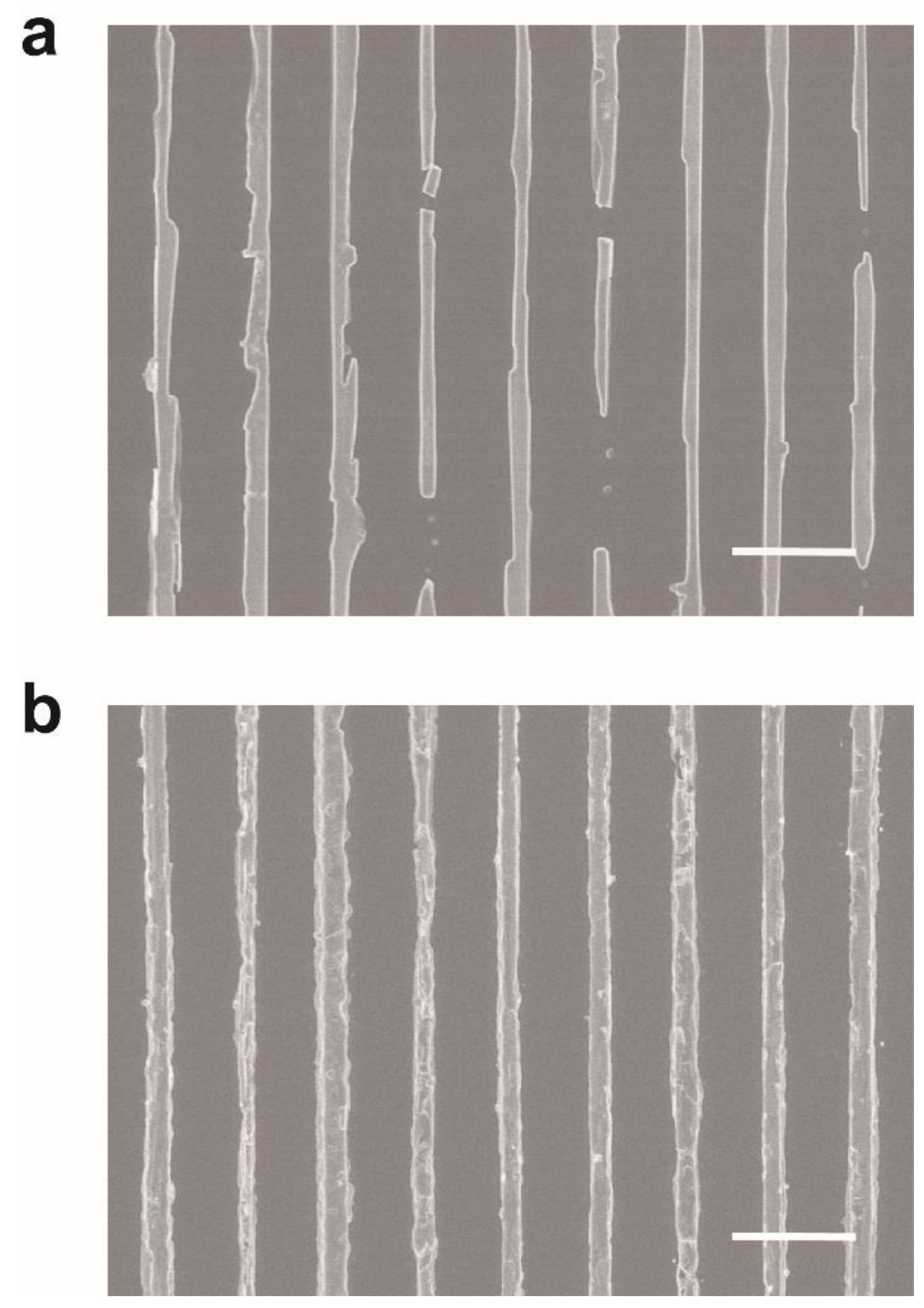

Figure S2. SEM images of (MTEA $)_{2}(\mathrm{MA})_{2} \mathrm{~Pb}_{3} \mathrm{I}_{10}$ perovskite nanowires with different solvents of a) DMF, b) DMSO. Scale bars, $10 \mu \mathrm{m}$. 
a

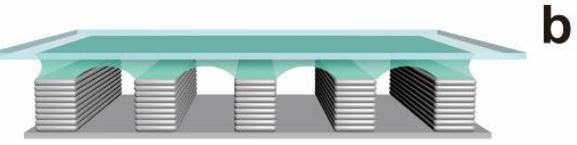

Liquid film

C

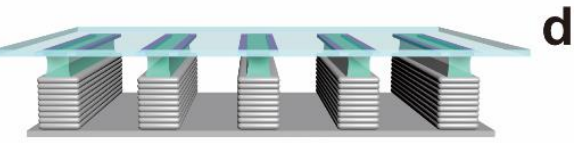

Nucleation at the liquid-air interface b

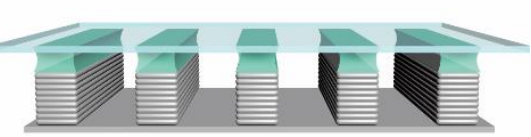

Capillary bridge

d

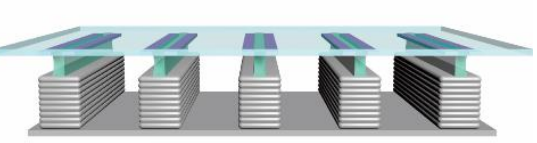

Growth along dewetting direction

Figure S3. Schematic illustration of the asymmetric-wettability micropillar assembly system for fabrication of 2D-perovskite single-crystalline nanowire arrays. a) A continuous film is confined between the micropillars and target substrates. b) Capillary bridges pinned on the top surfaces of micropillars. c) With the evaporation of solvents, the formation of capillary bridges and nucleation at the air-liquid interface can be observed. d) Coalescence of perovskite crystals of single-crystalline nanowires occur in the dewetting process. 

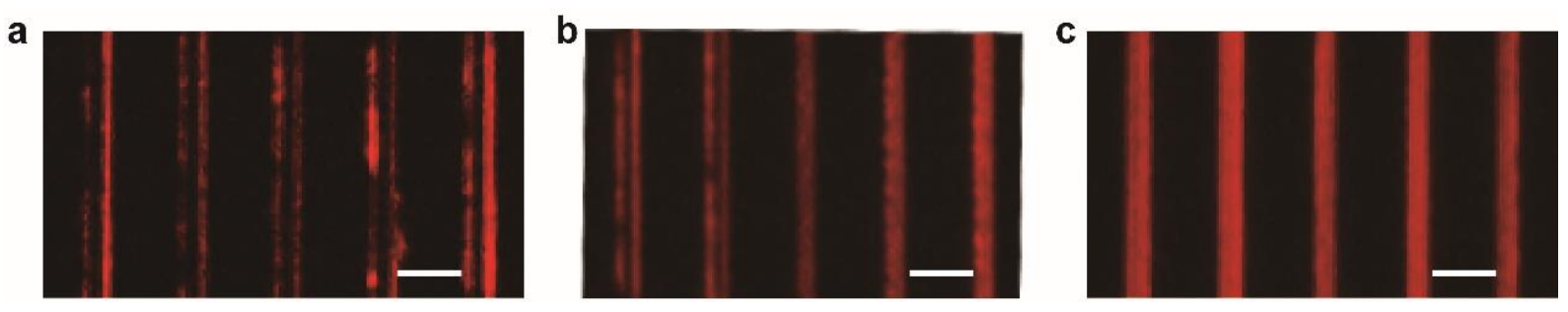

Figure S4. Optical microscope observation of dewetting, nucleation, and growth in capillary bridges. a) With the evaporation of solvents, the formation of capillary bridges and nucleation at the air-liquid interface can be observed. b) Coalescence of perovskite crystals and c) formation of single-crystalline nanowires occur in the dewetting process. Scale bars, $5 \mu \mathrm{m}$. 


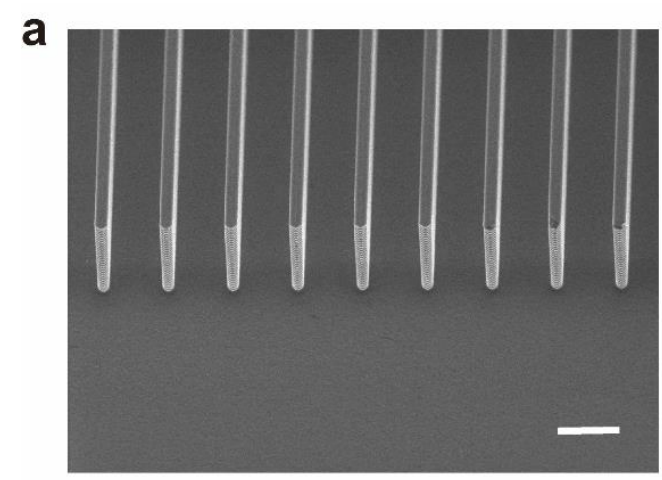

b

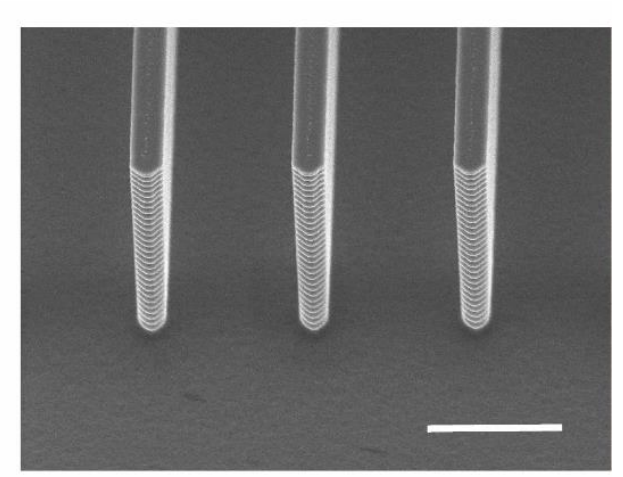

C

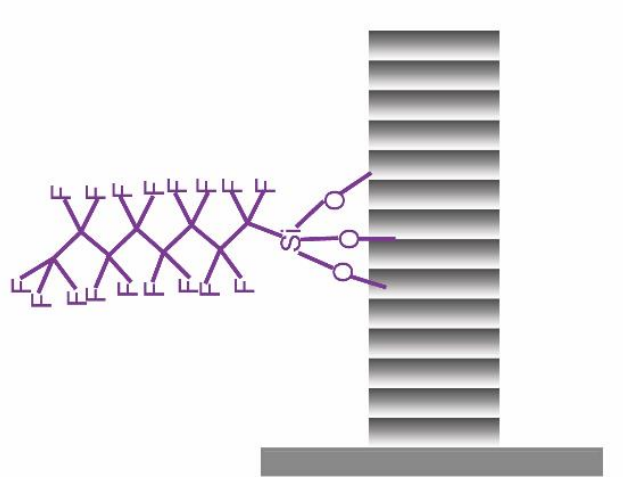

d

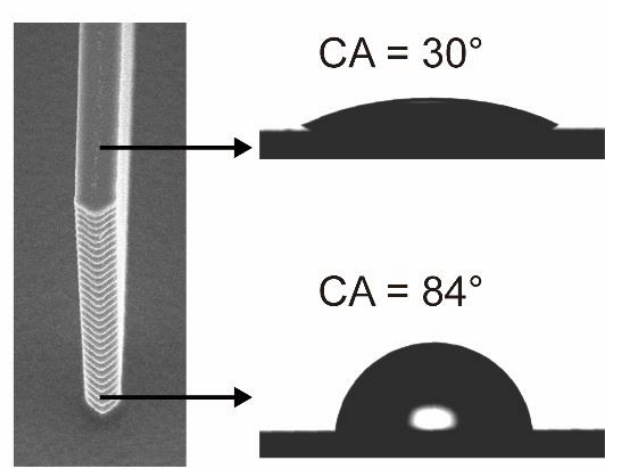

Figure S5. Morphology and the asymmetric wettability characterization of the template. a) SEM image of the topographical template with periodic line-shaped micropillars. b) Zoom-in SEM image of the topographical template. c) Schematic illustration of the template with FAS molecule modified on the sides leading to lyophobicity. d) The contact angle of MAAc on the top surfaces showing a contact angle of $30^{\circ}$, while the sidewalls demonstrating a contact angle of $84^{\circ}$. Scale bars, $5 \mu \mathrm{m}$. 
a

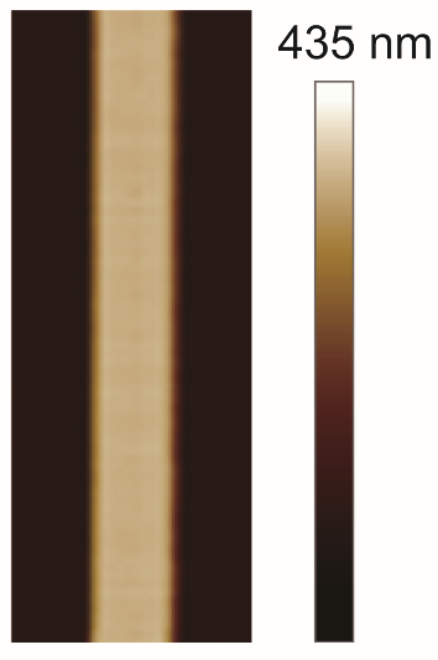

b

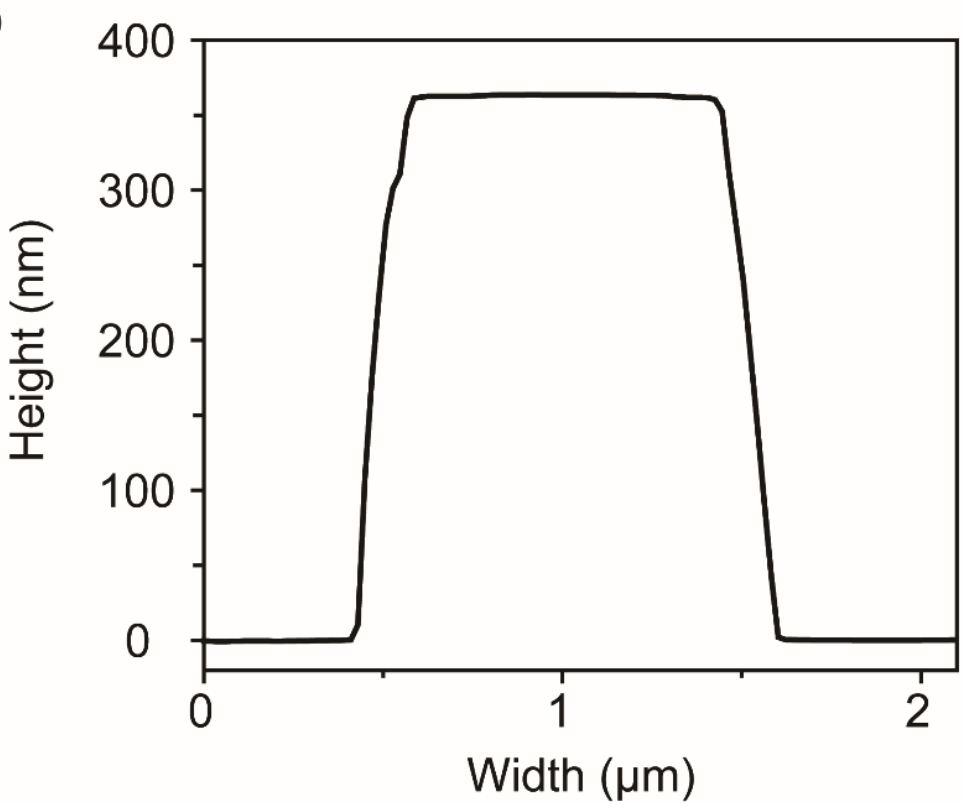

Figure S6. AFM topography (left) and the height diagrams (right) of $n=3$ perovskite nanowire.

By employing micropillars of $2 \mu \mathrm{m}$ and the perovskite precursor solution concentration of 20 $\mathrm{mg} \mathrm{mL} \mathrm{L}^{-1}$, the nanowire arrays of $363 \mathrm{~nm}$ in height and $1.2 \mu \mathrm{m}$ in width can be fabricated. 


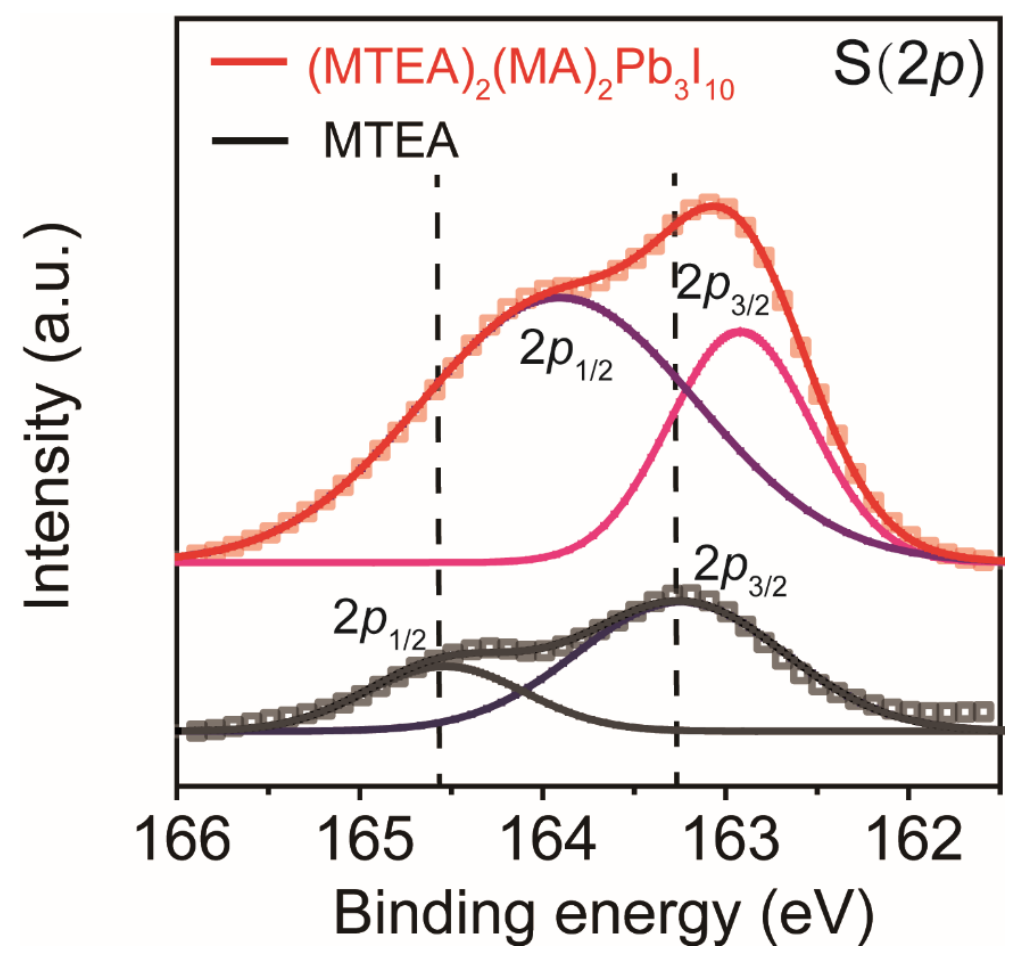

Figure S7. A comparison of X-ray photoelectron spectroscopy (XPS) spectra of the MTEAI films and (MTEA) $)_{2}(\mathrm{MA})_{2} \mathrm{~Pb}_{3} \mathrm{I}_{10}$ perovskite nanowires. 

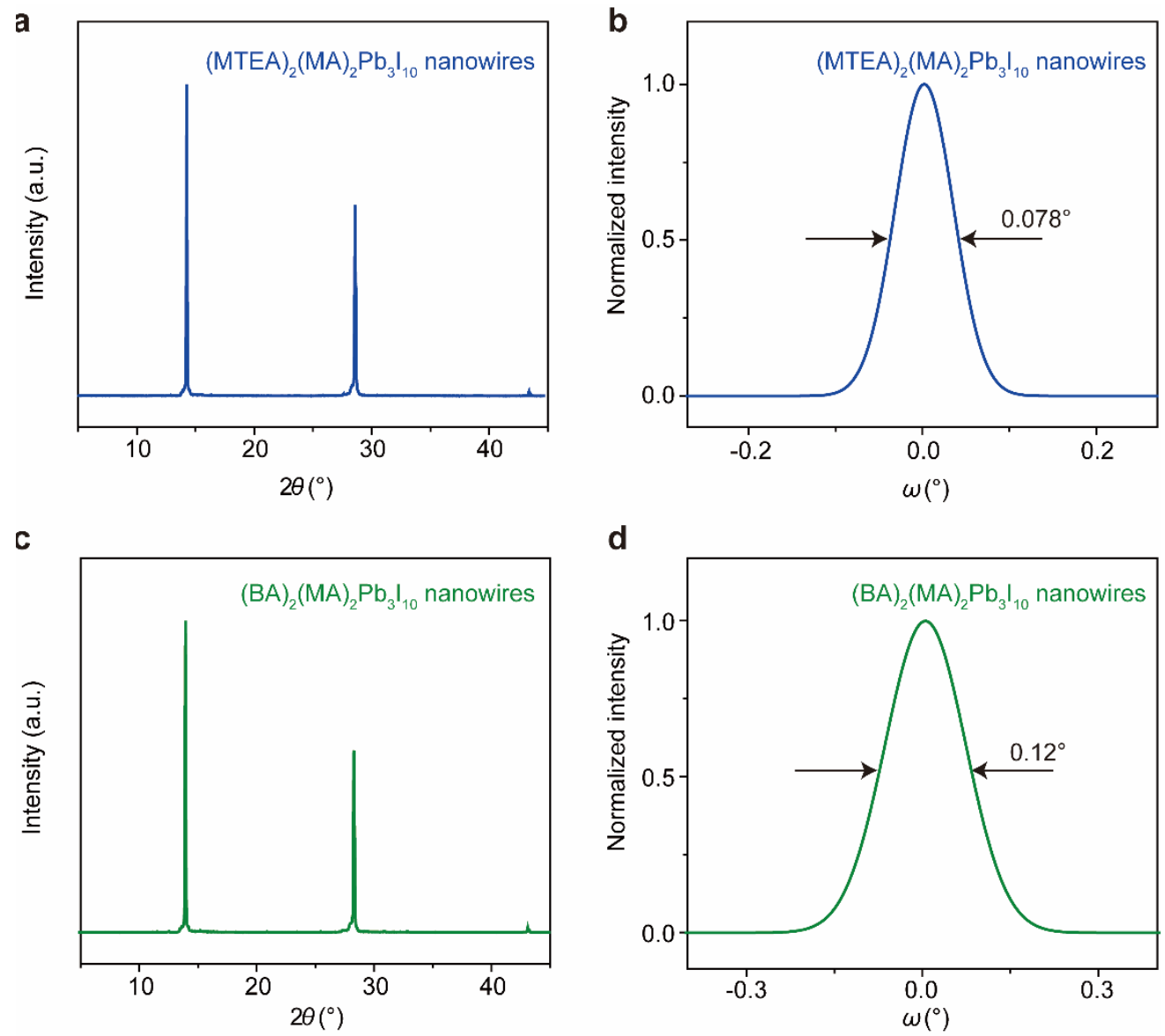

Figure S8. Crystallization characterization of perovskite nanowires. High-resolution XRD of a) $(\mathrm{MTEA})_{2}(\mathrm{MA})_{2} \mathrm{~Pb}_{3} \mathrm{I}_{10}$ perovskite nanowires and $\left.\mathrm{b}\right)(\mathrm{BA})_{2}(\mathrm{MA})_{2} \mathrm{~Pb}_{3} \mathrm{I}_{10}$ perovskite nanowires. The rocking curve of $b)(\mathrm{MTEA})_{2}(\mathrm{MA})_{2} \mathrm{~Pb}_{3} \mathrm{I}_{10}$ perovskite nanowires and d) $(\mathrm{BA})_{2}(\mathrm{MA})_{2} \mathrm{~Pb}_{3} \mathrm{I}_{10}$ perovskite nanowires. The narrower full width at half maximum (FWHM) for the (111) plane demonstrates the improved crystallinity of (MTEA $)_{2}(\mathrm{MA})_{2} \mathrm{~Pb}_{3} \mathrm{I}_{10}$ perovskite nanowires. 
a

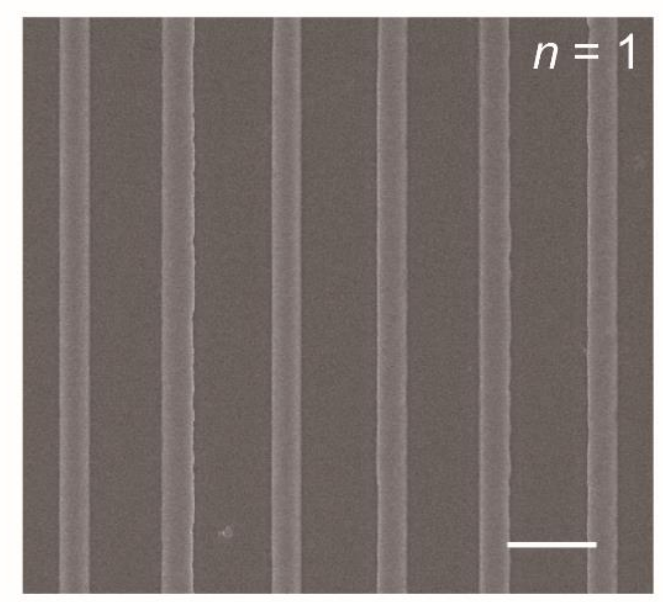

b

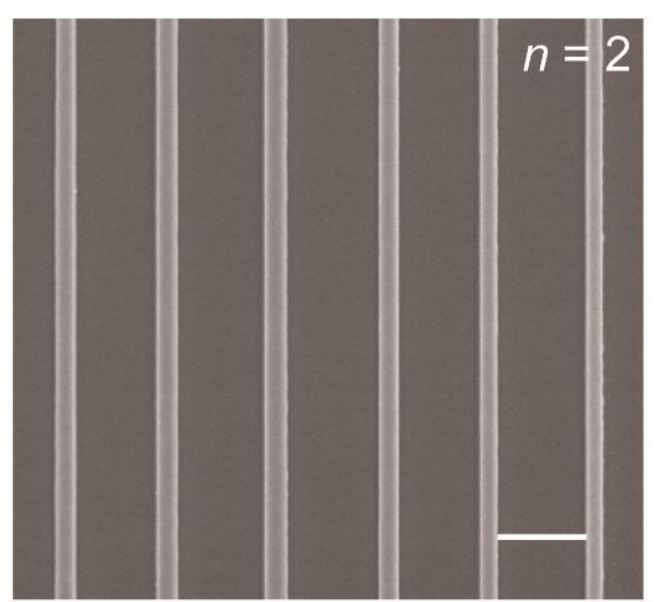

$n=1$
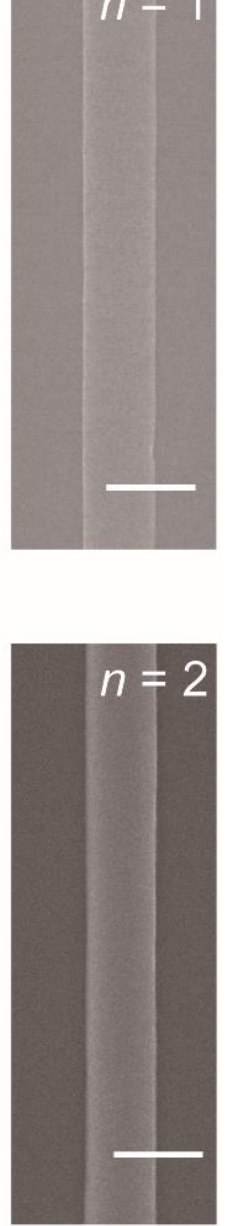

Figure S9. Representative SEM images of single-crystalline 2DRP perovskite nanowire arrays. Low-magnification (left) and zoom-in (SEM) images of nanowires of 2DRP perovskite (MTEA) $2(\mathrm{MA})_{n-1} \mathrm{~Pb}_{n} \mathrm{I}_{3 n+1}$ with a) $n=1$, b) $n=2$. Scale bars, $5 \mu \mathrm{m}$ (left) and $1 \mu \mathrm{m}$ (right). The micropillars are $2 \mu \mathrm{m}$ and the perovskite precursor solution concentration is $20 \mathrm{mg} \mathrm{mL}^{-1}$. 

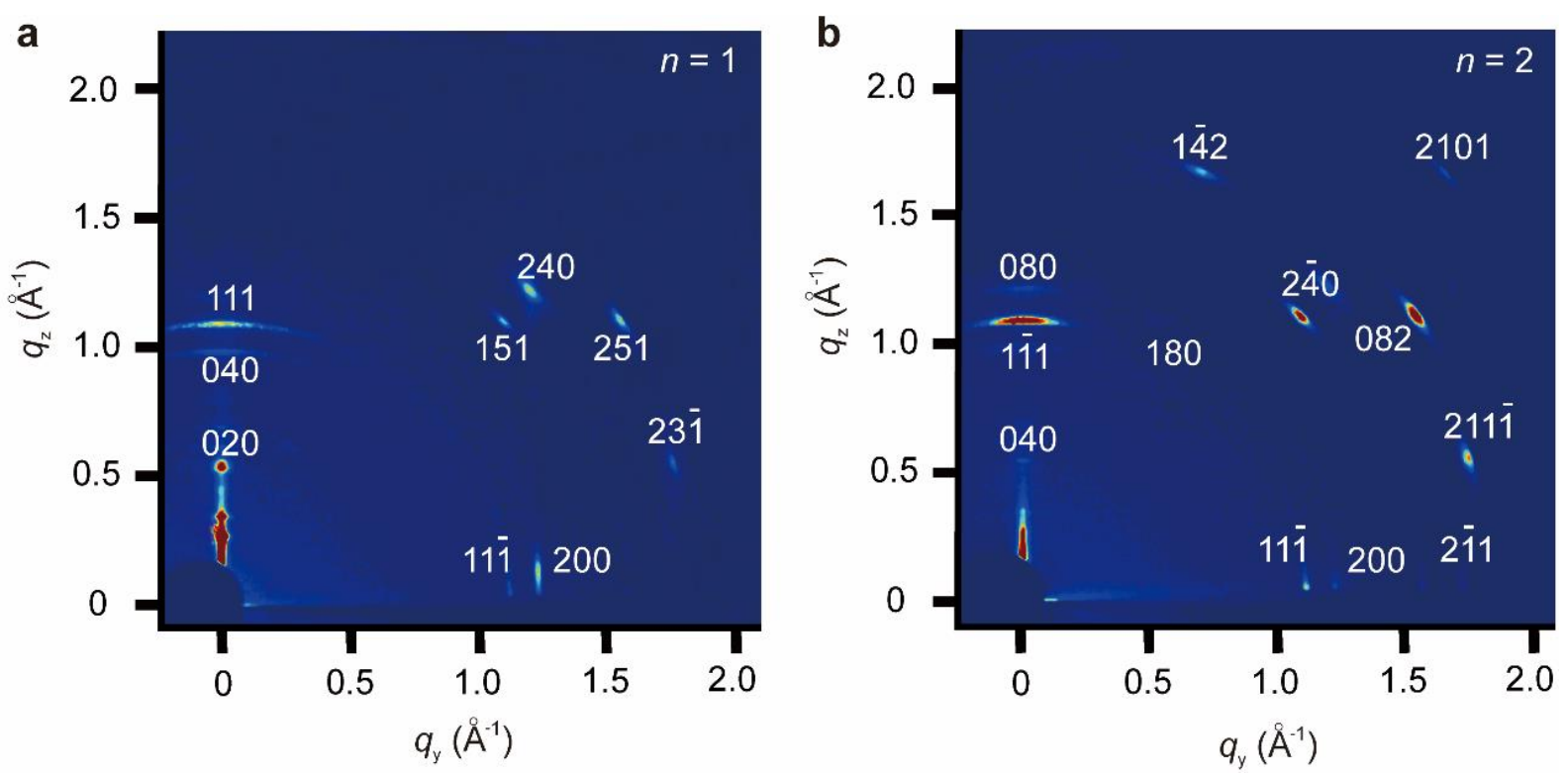

Figure S10. The grazing incidence wide-angle X-ray scattering patterns of a) $n=1$, b) $n=2$ layered-perovskite nanowires. 


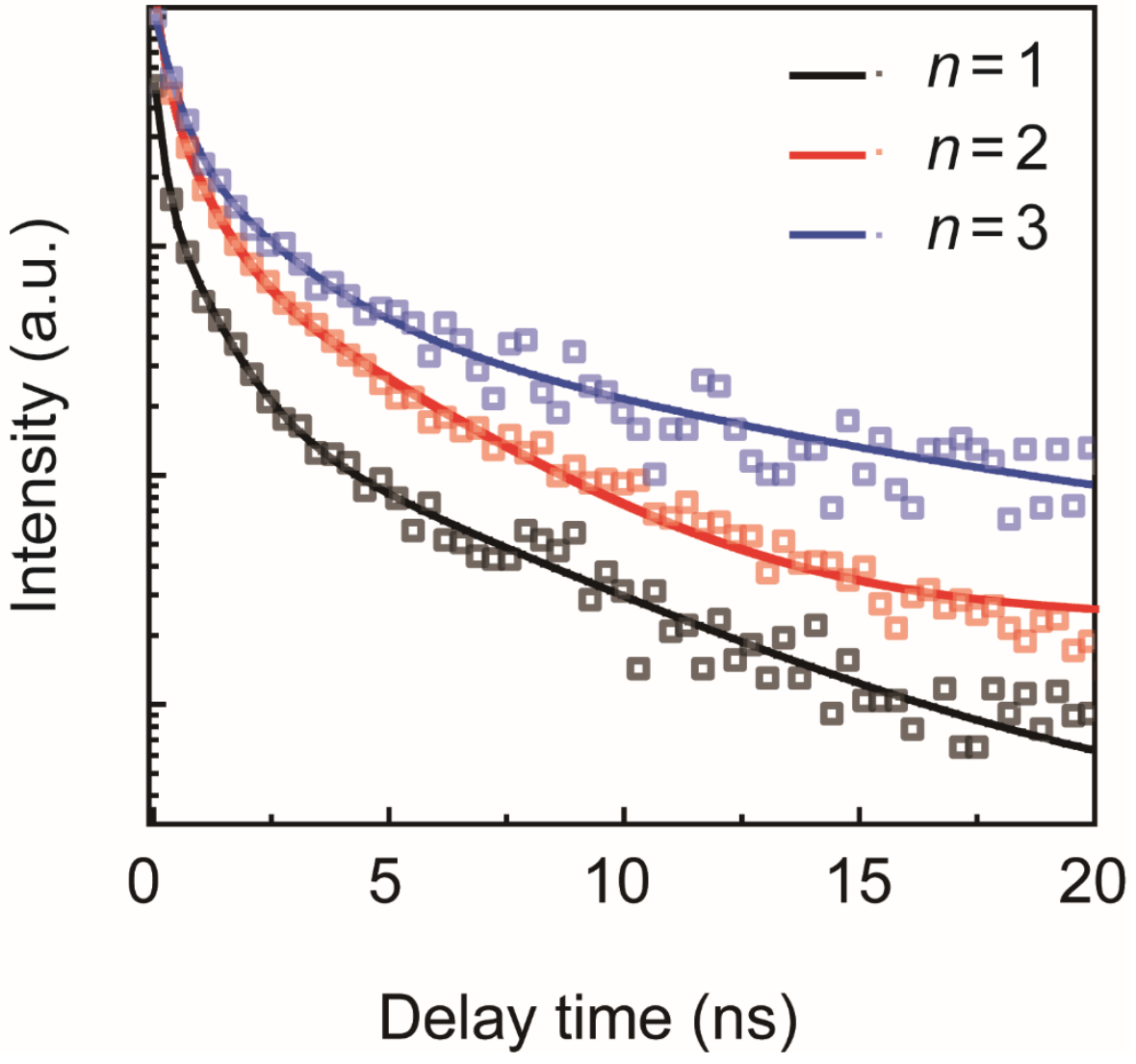

Figure S11. The PL dynamics of thin films fabricated by spin-coating method. 

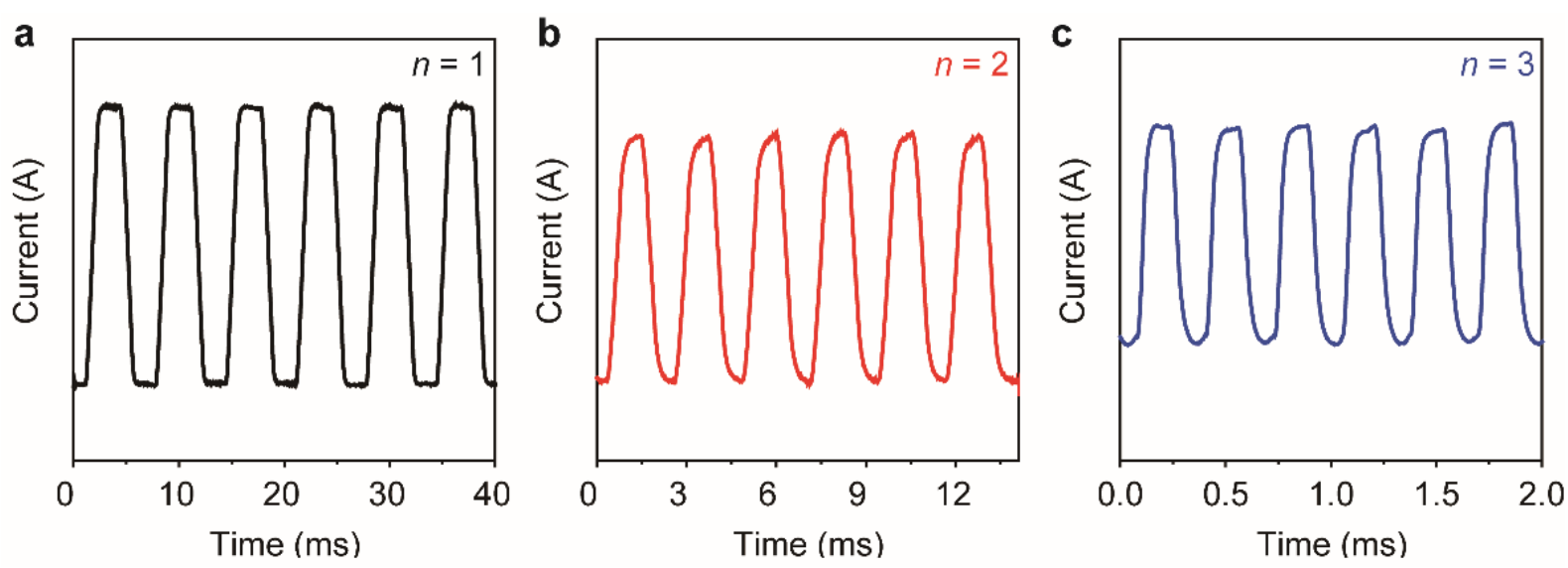

Figure S12. The time-resolved response of a) $n=1$, b) $n=2$, and c) $n=3$ perovskite nanowire photodetectors under periodically turning on and off the light under illumination power of 130 $\mathrm{mW} \mathrm{cm}^{-2}$. 

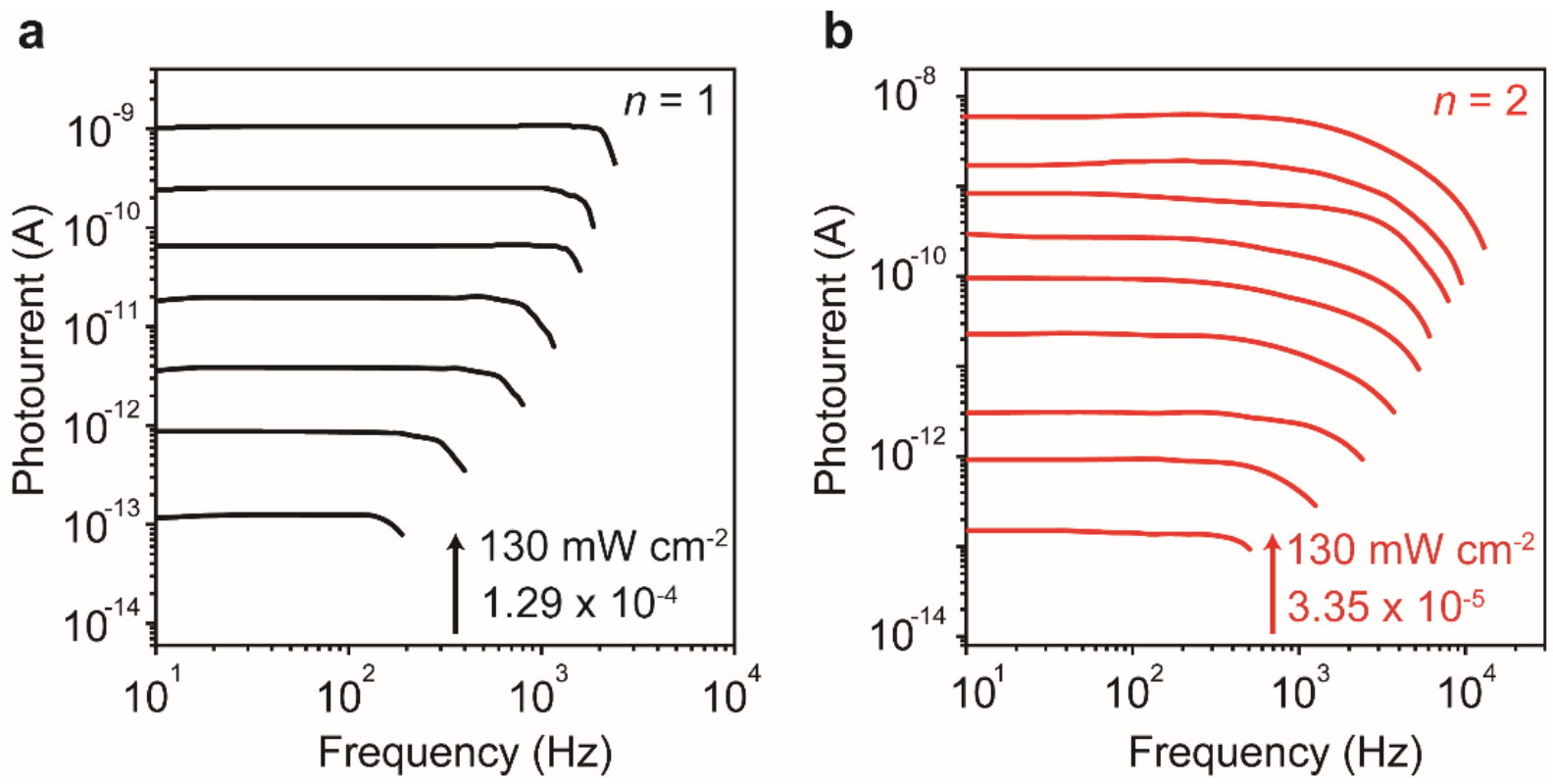

Figure S13. Frequency-modulated photocurrents of nanowire photodetectors. Frequencymodulated photocurrents of a) $n=1$, b) $n=2$ perovskite nanowire photodetectors under various irradiances at $5 \mathrm{~V}$ bias. 

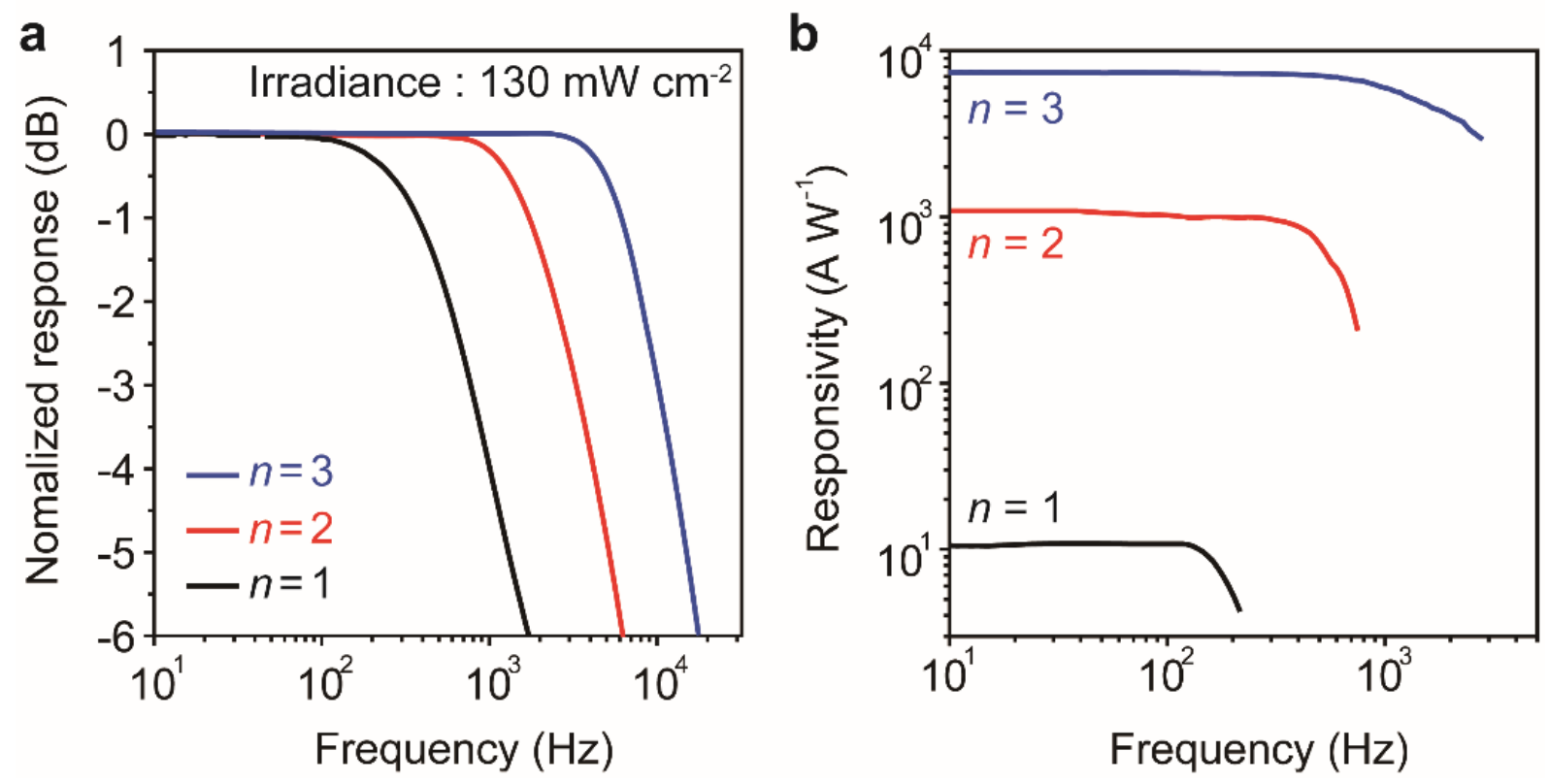

Figure S14. Frequency responses of nanowire photodetectors. a) Normalized responses of $n=$ 1-3 perovskite nanowire devices under irradiance of $130 \mathrm{~mW} \mathrm{~cm} \mathrm{~cm}^{-2}$ at various frequencies, showing $3 \mathrm{~dB}$ bandwidth of $n=3$ perovskite nanowires is $10.3 \mathrm{kHz}$, which is in good accordance with the faster response speed. b) Frequency-modulated responsivities of $n=1-3$ perovskite nanowire devices. 

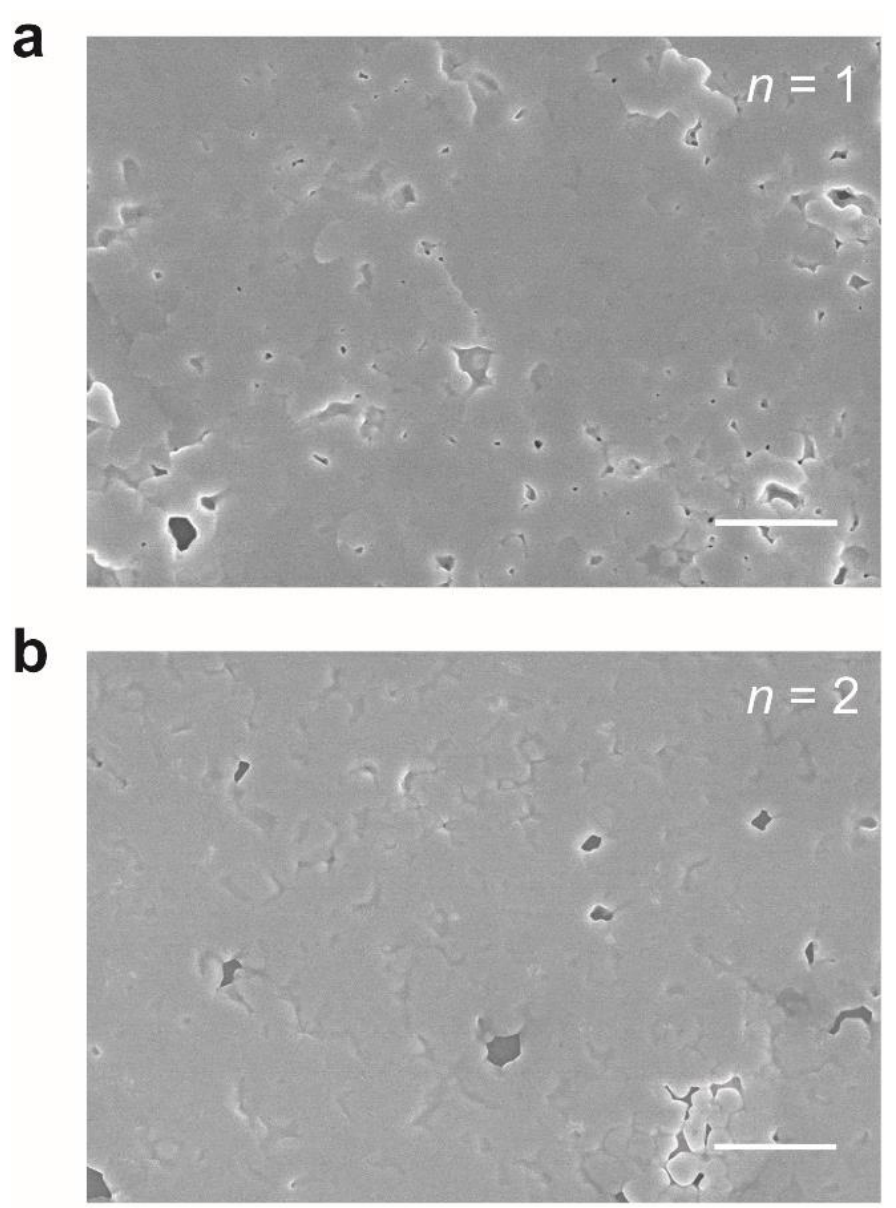

Figure S15. SEM images of $n=1-2$ layered perovskite thin films. Thin films fabricated by spin-coating method are polycrystalline with ubiquitous grain boundaries. Scale bars, $5 \mu \mathrm{m}$. 

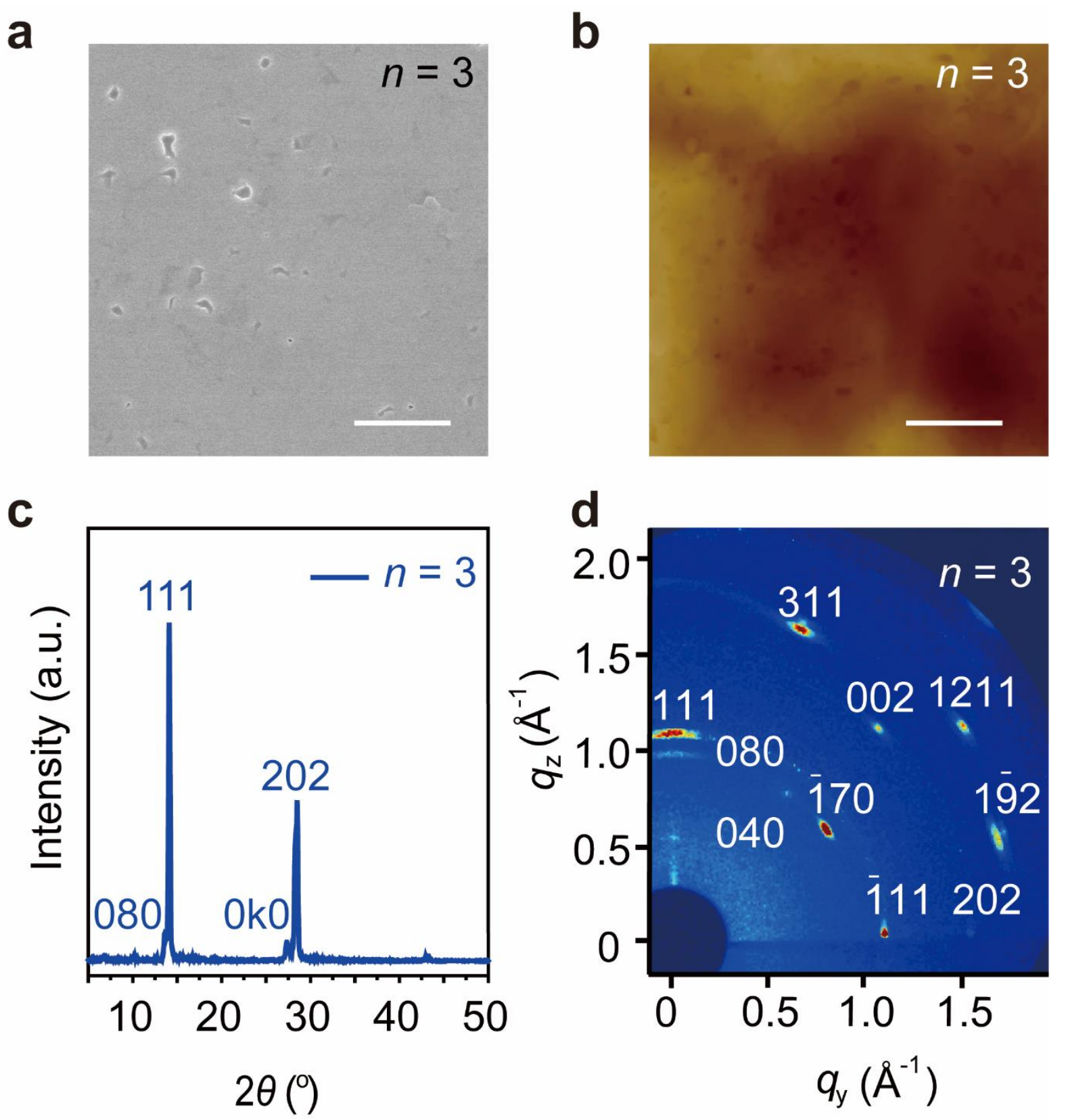

Figure S16. Morphology and crystallographic orientation of $n=3$ 2DRP perovskite thin film.

a) SEM image, b) AFM image, c) XRD diagram, and d) GIWAXS pattern of $n=3$ perovskite thin film. Scale bars, $2 \mu \mathrm{m}$. The thin film fabricated by the spin-coating method is polycrystalline with ubiquitous grain boundaries, which mixed crystallographic orientations of (101) and (010), presenting poor crystallinity. 

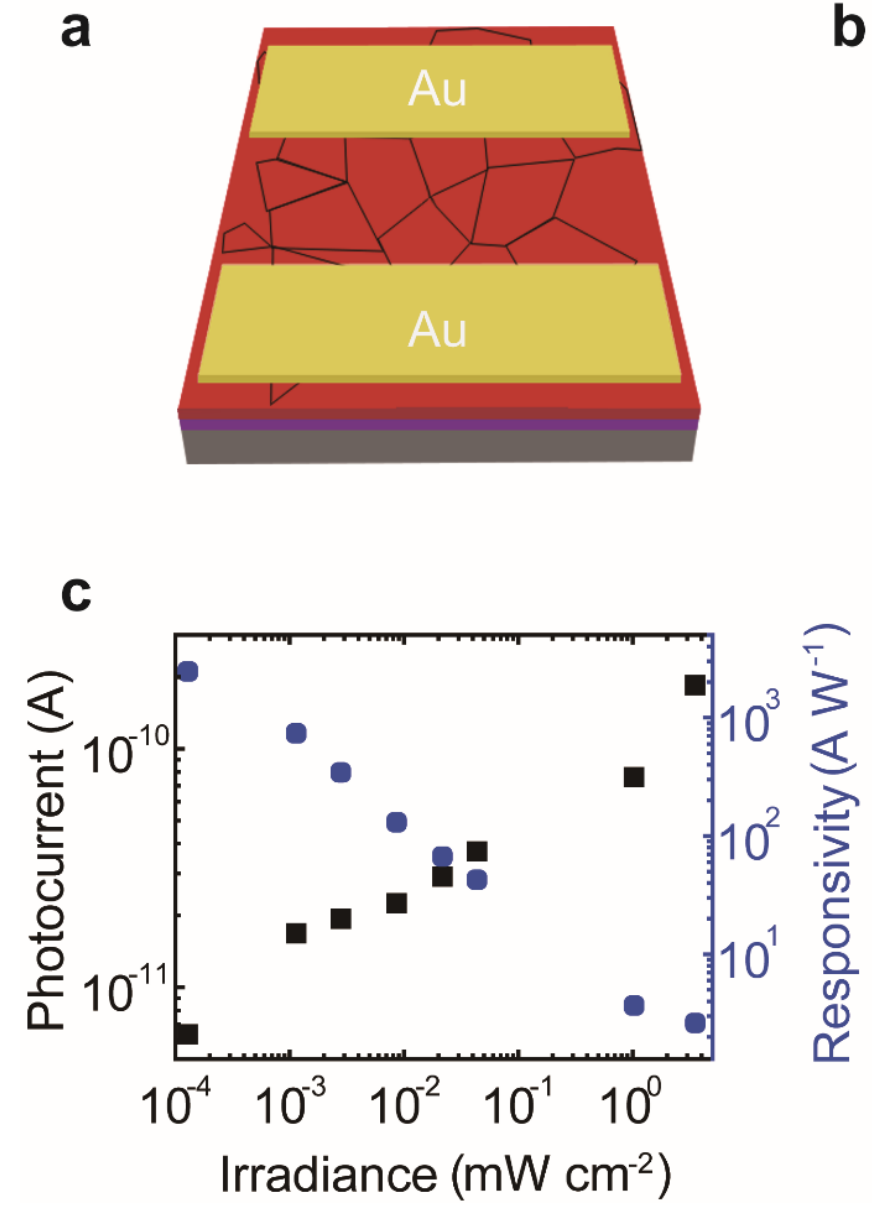

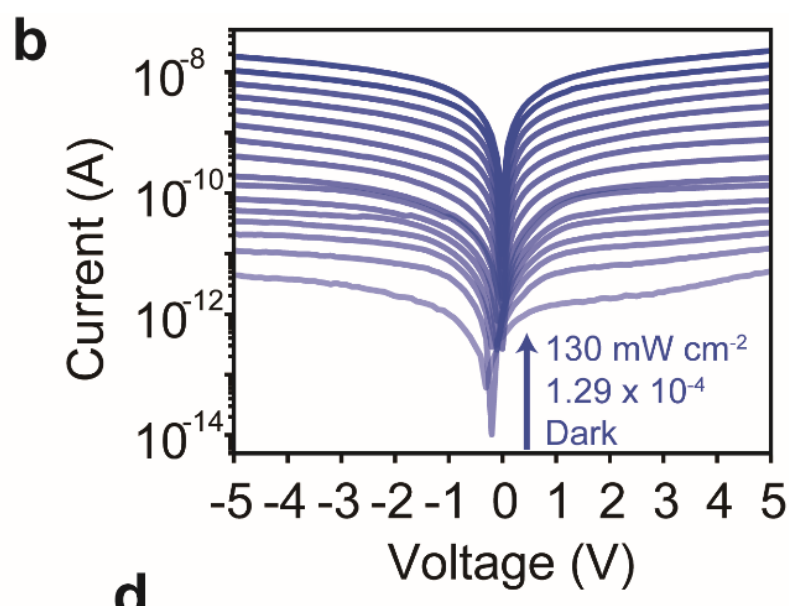

d

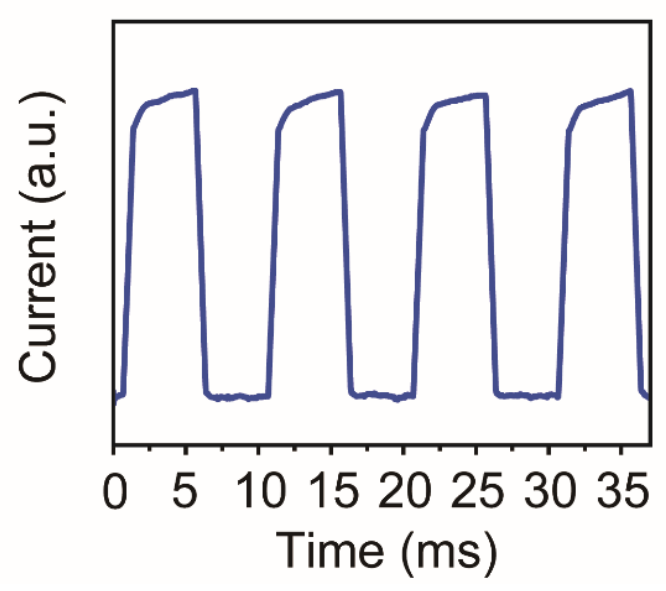

Figure S17. Photodetector performance of $n=3$ 2DRP perovskite thin film. a) Schematic illustration of a device. b) The typical logarithmic $I-V$ curve of $n=3$ 2DRP perovskite thin film under dark and different irradiances (530 nm LED incident light). c) Photocurrent and responsivity of photodetector under different irradiances. d) I-t response of photodetector. 

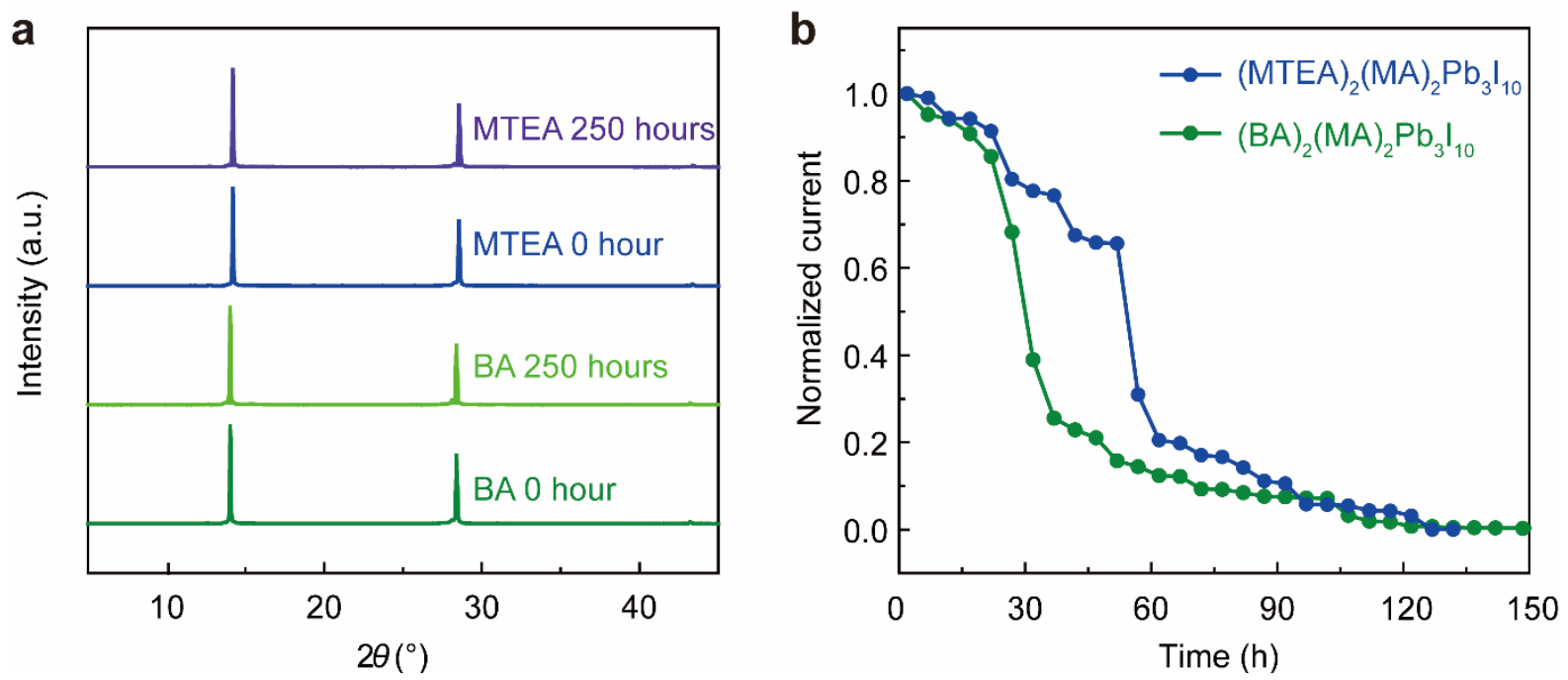

Figure S18. a) XRD patterns of $(\mathrm{BA})_{2}(\mathrm{MA})_{2} \mathrm{~Pb}_{3} \mathrm{I}_{10}$ and (MTEA) $)_{2}(\mathrm{MA})_{2} \mathrm{~Pb}_{3} \mathrm{I}_{10}$ perovskite nanowires after exposure to $\mathrm{RH} 40 \%$ at 25-30 $\square$ for different times. b) The normalized current variation curves of photodetectors stored at $80 \square$ with a $\mathrm{N}_{2}$-filled atmosphere. 


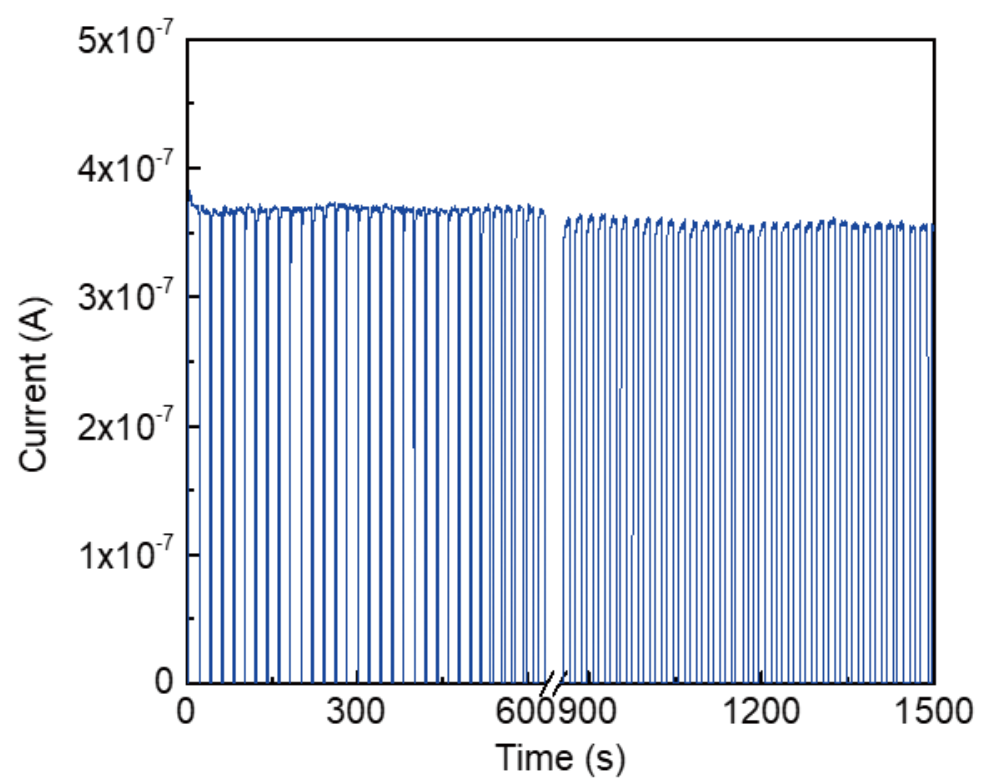

Figure S19. Photocurrents of the photodetectors under $530 \mathrm{~nm}$ light for on/off switching cycles with remaining time of $1500 \mathrm{~s}$. 
Table S1. The biexponential fitting results of time-resolved PL experiments. The TRPL are fitted with a biexponential function, $I=a \exp \left(-t / \tau_{1}\right)+b \exp \left(-t / \tau_{2}\right)$, where $a$ and $b$ are amplitudes, $t$ the delay time, $\tau_{1} \tau_{2}$, the delay time. $\tau_{\mathrm{e}}$ is the delay time at the PL intensity reduced to $1 / \mathrm{e}$ of its initial value.

\begin{tabular}{cccc}
\hline Sample & $\boldsymbol{\tau}_{\mathbf{1}}(\mathbf{n s})$ & $\boldsymbol{\tau}_{\mathbf{2}}(\mathbf{n s})$ & $\boldsymbol{\tau}_{\mathbf{e}}(\mathbf{n s})$ \\
\hline$n=1$ nanowire & 1.017 & 10.654 & 3.424 \\
$n=2$ nanowire & 2.435 & 12.537 & 5.821 \\
$n=3$ nanowire & 3.818 & 20.280 & 6.132 \\
$n=1$ thin film & 0.212 & 1.701 & 0.315 \\
$n=2$ thin film & 0.259 & 2.052 & 0.337 \\
$n=3$ thin film & 0.472 & 3.945 & 0.707 \\
\hline
\end{tabular}


Table S2. Device performance parameters comparison between previously reported 2D/3D perovskite photodetectors and the present (MTEA $)_{2}(\mathrm{MA})_{2} \mathrm{~Pb}_{3} \mathrm{I}_{10}$ device.

\begin{tabular}{|c|c|c|c|c|c|}
\hline $\begin{array}{c}\text { Materials/ } \\
\text { dimensionality }\end{array}$ & $\begin{array}{c}\text { Device } \\
\text { structure }\end{array}$ & $\begin{array}{l}\text { Responsivity } \\
\text { (A/W) }\end{array}$ & $\begin{array}{c}\text { Detectivity } \\
\text { (Jones) }\end{array}$ & $\begin{array}{c}\text { Response } \\
\text { speed } \\
\text { (rise/decay) }\end{array}$ & Ref. \\
\hline $\begin{array}{c}\mathrm{MAPbBr}_{3-\mathrm{x}} \mathrm{Cl}_{\mathrm{x}} \\
\mathrm{MAPbI}_{3-\mathrm{x}} \mathrm{Br}_{\mathrm{x}} / 3 \mathrm{D}\end{array}$ & photodiode & - & $2 \times 10^{10}$ & - & 1 \\
\hline $\mathrm{MAPbI}_{3-\mathrm{x}} \mathrm{Br}_{\mathrm{x}} / 3 \mathrm{D}$ & photodiode & - & $2 \times 10^{11}$ & $1.8 \mu \mathrm{s} / 1.5 \mu \mathrm{s}$ & 2 \\
\hline $\mathrm{MAPbBr} 3 / 3 \mathrm{D}$ & photoconductor & $4 \times 10^{3}$ & $10^{13}$ & $-/ 25 \mu \mathrm{s}$ & 3 \\
\hline $\mathrm{CsPbBr}_{3} / 3 \mathrm{D}$ & photoconductor & $1 \times 10^{3}$ & - & $21.5 \mu \mathrm{s} / 23.4 \mu \mathrm{s}$ & 4 \\
\hline $\mathrm{MAPbI}_{3} / 3 \mathrm{D}$ & photoconductor & 13.57 & $5.25 \times 10^{12}$ & $80 \mu \mathrm{s} / 240 \mu \mathrm{s}$ & 5 \\
\hline $\mathrm{MAPbI}_{3} / 3 \mathrm{D}$ & photoconductor & 4.95 & $2 \times 10^{13}$ & $<0.1 \mathrm{~ms}$ & 6 \\
\hline$\left(\mathrm{C}_{4} \mathrm{H}_{9} \mathrm{NH}_{3}\right)_{2} \mathrm{PbBr}_{4} / 2 \mathrm{D}$ & photoconductor & $2.1 \times 10^{3}$ & - & - & 7 \\
\hline$\left(\mathrm{C}_{6} \mathrm{H}_{5} \mathrm{C}_{2} \mathrm{H}_{4} \mathrm{NH}_{3}\right)_{2} \mathrm{PbI}_{4} / 2 \mathrm{D}$ & photoconductor & 98.17 & $1.62 \times 10^{15}$ & $64 \mu \mathrm{s} / 52 \mu \mathrm{s}$ & 8 \\
\hline$(\mathrm{BA})_{2}(\mathrm{MA})_{2} \mathrm{~Pb}_{3} \mathrm{Br}_{10} / 2 \mathrm{D}$ & photoconductor & - & $3.6 \times 10^{10}$ & $150 \mu \mathrm{s} / 570 \mu \mathrm{s}$ & 9 \\
\hline$(\mathrm{BA})_{2}(\mathrm{MA}) \mathrm{Pb}_{2} \mathrm{I}_{7} / 2 \mathrm{D}$ & photodiode & & $10^{11}$ & $125 \mathrm{~ms} / 74 \mathrm{~ms}$ & 10 \\
\hline$(\mathrm{BA})_{2}(\mathrm{MA})_{2} \mathrm{~Pb}_{3} \mathrm{I}_{10} / 2 \mathrm{D}$ & photoconductor & $10^{4}$ & $4 \times 10^{10}$ & - & 11 \\
\hline$(\mathrm{BA})_{2}(\mathrm{MA})_{2} \mathrm{~Pb}_{3} \mathrm{I}_{10} / 2 \mathrm{D}$ & photoconductor & $1.28 \times 10^{-2}$ & - & $10 \mathrm{~ms} / 7.5 \mathrm{~ms}$ & 12 \\
\hline$(\mathrm{BA})_{2}(\mathrm{MA})_{3} \mathrm{~Pb}_{4} \mathrm{I}_{13} / 2 \mathrm{D}$ & photoconductor & $1.5 \times 10^{4}$ & $7 \times 10^{15}$ & $27.6 \mu \mathrm{s} / 24.5 \mu \mathrm{s}$ & 13 \\
\hline$(\mathrm{ThMA})_{2}(\mathrm{MA})_{2} \mathrm{~Pb}_{3} \mathrm{I}_{10} / 2 \mathrm{D}$ & photoconductor & $1.1 \times 10^{4}$ & $9.1 \times 10^{15}$ & $36.2 \mu \mathrm{s} / 31.5 \mu \mathrm{s}$ & 14 \\
\hline$(\mathrm{MTEA})_{2}(\mathrm{MA})_{2} \mathrm{~Pb}_{3} \mathrm{I}_{10} / 2 \mathrm{D}$ & photoconductor & $7.3 \times 10^{3}$ & $3.9 \times 10^{15}$ & $40 \mu \mathrm{s} / 52.2 \mu \mathrm{s}$ & $\begin{array}{l}\text { This } \\
\text { work }\end{array}$ \\
\hline
\end{tabular}

1. Fang, Y.; Dong, Q.; Shao, Y.; Yuan, Y.; Huang, J., Highly Narrowband Perovskite SingleCrystal Photodetectors Enabled by Surface-Charge Recombination. Nat. Photon. 2015, 9, 679686.

2. Lin, Q.;Armin, A.; Burn, P. L.; Meredith, P., Filterless Narrowband Visible Photodetectors. Nat. Photon. 2015, 9, 687-694.

3. Saidaminov, M. I.; Adinolfi, V.; Comin, R.; Abdelhady, A. L.; Peng, W.; Dursun, I.; Yuan, 
M.; Hoogland, S.; Sargent, E. H.; Bakr, O. M., Planar-Integrated Single-Crystalline Perovskite Photodetectors. Nat. Commun. 2015, 6, 8724.

4. Feng, J.; Yan, X.; Liu, Y.; Gao, H.; Wu, Y.; Su, B.; Jiang, L., Crystallographically Aligned Perovskite Structures for High-Performance Polarization-Sensitive Photodetectors. Adv. Mater. 2017, 29, 1605993.

5. Deng, W.; Zhang, X.; Huang, L.; Xu, X.; Wang, L.; Wang, J.; Shang, Q.; Lee, S.-T.; Jie, J., Aligned Single-Crystalline Perovskite Microwire Arrays for High-Performance Flexible Image Sensors with Long-Term Stability. Adv. Mater. 2016, 28, 2201-2208.

6. Gao, L.; Zeng, K.; Guo, J.; Ge, C.; Du, J.; Zhao, Y.; Chen, C.; Deng, H.; He, Y.; Song, H.; Niu, G.; Tang, J., Passivated Single-Crystalline $\mathrm{CH}_{3} \mathrm{NH}_{3} \mathrm{PbI}_{3}$ Nanowire Photodetector with High Detectivity and Polarization Sensitivity. Nano Lett. 2016, 16, 7446-7454.

7. Tan, Z.; Wu, Y.; Hong, H.; Yin, J.; Zhang, J.; Lin, L.; Wang, M.; Sun, X.; Sun, L.; Huang, Y.; Liu, K.; Liu, Z.; Peng, H., Two-Dimensional $\left(\mathrm{C}_{4} \mathrm{H}_{9} \mathrm{NH}_{3}\right)_{2} \mathrm{PbBr}_{4}$ Perovskite Crystals for High-Performance Photodetector. J. Am. Chem. Soc. 2016, 138, 16612-16615.

8. Liu, Y.; Zhang, Y.; Yang, Z.; Ye, H.; Feng, J.; Xu, Z.; Zhang, X.; Munir, R.; Liu, J.; Zuo, P.; Li, Q.; Hu, M.; Meng, L.; Wang, K.; Smilgies, D.-M.; Zhao, G.; Xu, H.; Yang, Z.; Amassian, A.; Li, J.; Zhao, K.; Liu, S., Multi-Inch Single-Crystalline Perovskite Membrane for HighDetectivity Flexible Photosensors. Nat. Commun. 2018, 9, 5302.

9. Li, L.; Sun, Z.; Wang, P.; Hu, W.; Wang, S.; Ji, C.; Hong, M.; Luo, J., Tailored Engineering of an Unusual $\left(\mathrm{C}_{4} \mathrm{H}_{9} \mathrm{NH}_{3}\right)_{2}\left(\mathrm{CH}_{3} \mathrm{NH}_{3}\right)_{2} \mathrm{~Pb}_{3} \mathrm{Br}_{10}$ Two-Dimensional Multilayered Perovskite Ferroelectric for a High-Performance Photodetector. Angew Chem. Int. Ed. 2017, 56, 1215012154.

10. Li, J.; Wang, J.; Ma, J.; Shen, H.; Li, L.; Duan, X.; Li, D., Self-Trapped State Enabled Filterless Narrowband Photodetections in 2D Layered Perovskite Single Crystals. Nat. Commun. 2019, 10, 806.

11. Fu, Q.; Wang, X.; Liu, F.; Dong, Y.; Liu, Z.; Zheng, S.; Chaturvedi, A.; Zhou, J.; Hu, P.; Zhu, Z.; Bo, F.; Long, Y.; Liu, Z., Ultrathin Ruddlesden-Popper Perovskite Heterojunction for Sensitive Photodetection. Small 2019, 15, 1902890.

12. Zhou, J.; Chu, Y.; Huang, J., Photodetectors Based on Two-Dimensional Layer-Structured Hybrid Lead Iodide Perovskite Semiconductors. ACS Appl. Mater. Interfaces. 2016, 8, 25660- 
25666.

13. Feng, J.; Gong, C.; Gao, H.; Wen, W.; Gong, Y.; Jiang, X.; Zhang, B.; Wu, Y.; Wu, Y.; Fu, H.; Jiang, L.; Zhang, X., Single-Crystalline Layered Metal-Halide Perovskite Nanowires for Ultrasensitive Photodetectors. Nat Electron 2018, 1, 404-410.

14. Zhao, Y.; Qiu, Y.; Gao, H.; Feng, J.; Chen, G.; Jiang, L.; Wu, Y., Layered-Perovskite Nanowires with Long-Range Orientational Order for Ultrasensitive Photodetectors. Adv. Mater. 2020, 32, 1905298. 